\title{
Rock Physics Modeling and Seismic Interpretation to Estimate Shally Cemented Zone in Carbonate Reservoir Rock
}

\author{
Handoyo $^{1, *}$, M Rizki Sudarsana $^{2}$, and Restu Almiati ${ }^{1}$ \\ ${ }^{1}$ Geophysical Engineering, Institut Teknologi Sumatera, South Lampung, Indonesia \\ ${ }^{2}$ Geophysics, Universitas Padjajaran, West Java, Indonesia
}

*Corresponding author's email: handoyo_1906@yahoo.com

Tel.: +6285295400039

Received: Oct 1, 2016. Revised : 12 Nov 2016, Accepted: Nov 20, 2016, Published: 1 Dec 2016

DOI : 10.24273/jgeet.2016.11.6

Abstract

Carbonate rock are important hydrocarbon reservoir rocks with complex texture and petrophysical properties (porosity and permeability). These complexities make the prediction reservoir characteristics (e.g. porosity and permeability) from their seismic properties more difficult. The goal of this paper are to understanding the relationship of physical properties and to see the signature carbonate initial rock and shally-carbonate rock from the reservoir.

To understand the relationship between the seismic, petrophysical and geological properties, we used rock physics modeling from ultrasonic P- and S- wave velocity that measured from log data. The measurements obtained from carbonate reservoir field (gas production). X-ray diffraction and scanning electron microscope studies shown the reservoir rock are contain wackestone-packstone content. Effective medium theory to rock physics modeling are using Voigt, Reuss, and Hill.

It is shown the elastic moduly proposionally decrease with increasing porosity. Elastic properties and wave velocity are decreasing proporsionally with increasing porosity and shally cemented on the carbonate rock give higher elastic properties than initial carbonate non-cemented. Rock physics modeling can separated zones which rich of shale and less of shale.

Keywords: elastic modulus, porosity, velocity, and shally-cemented.

\section{Introduction}

Reservoir rocks possess certain characteristic which can be identified by several physical parameters. Among many of the physical characteristics provided as information regarding physical parameters from reservoir rock is very essential to understand the reservoir better.

In this study, there will be rock physics modeling to differentiate zones which rich of shale and slight of shale. The study areas was located in Java Sea (Figure 1). The purpose of this study is to : (1) knowing the characteristics of elastic rock paramameter; (2) predicting the mineral-rich shale

minerals constituent of rock complex, carbonate rocks also have a variety of complex pore geometry. The only way to make rock physics modeling was using effective medium theory. Illustration simplification model of carbonate rocks are shown by Figure 2 . Lithology reservoir carbonate in research area was a carbonate wackestonemudstone which interspersed with mineral dolomite and calcite.

The simple bounds for an isotropic linear elastic composite, defined as giving the narrowest possible range without specifying anything about the geometries of the constituents, are the simple effectif medium theory is the Voigt bound (illustrated by Figure 1). The Voigt $\left(M_{v}\right)$ and Reuss parameters are the porosity and permeability. According to [7], the characterization is a process of elaborating its characteristic qualitatively and quantitatively by using the available data. The

zone as cement and a mineral-slight shale zone; (3) interpreting the existence of shale gas reservoir in the study area.

\section{Data and Basic Theory}

Complex carbonate rocks is very difficult to be modeled. In addition to the types of

$\left(M_{R}\right)$ bound calculated effective elastic modulus, from the volum fraction $\mathrm{N}$ phase $\mathrm{fi}$, and elastic modulus $\mathrm{N}$ phase fraction $\mathrm{Mi}$ as follows [6]:

$$
\begin{aligned}
M_{V} & =\sum_{N=1}^{N} f_{i} M_{i} \\
\frac{1}{M_{R}} & =\sum_{N=1}^{N} \frac{f_{i}}{M_{i}}
\end{aligned}
$$

The velocities of various types of seismic waves in homogeneous, isotropic, elastic media are given by: 


$$
\begin{aligned}
& V_{p}=\sqrt{\frac{K+\frac{4}{3} \mu}{\rho}} \\
& V_{S}=\sqrt{\frac{\mu}{\rho}}
\end{aligned}
$$

Jizba [5] studied the effect of cementation on rock physics properties of sandstones, Avseth and
Mavko [2] showed that the scatter observed in velocity-porosity data can be decomposed into depth-lines, while Dvorkin and Nur [4] showed mathematically how cement could cause complexity in the velocity-porosity plane depending on cement location and mineral composition (Figure 3). Rock texture and lithology also greatly affect the observed scatter (e.g., Bryant and Raikes [3]; Vernik [8]; Anselmetti and Eberli [1]).

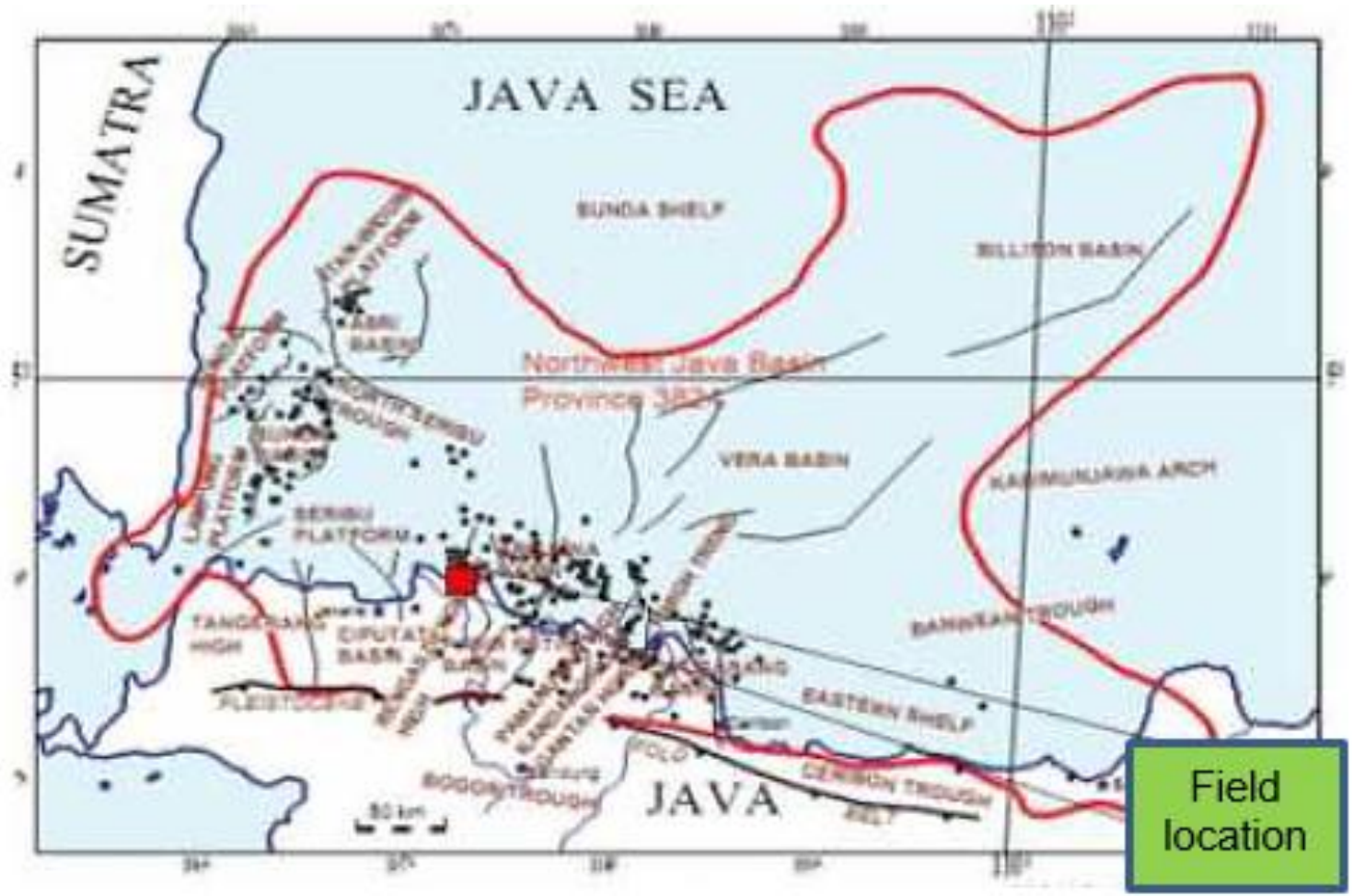

Fig 1. The study area which located in Java Sea known as a carbonate rock reservoirs that produce gas.

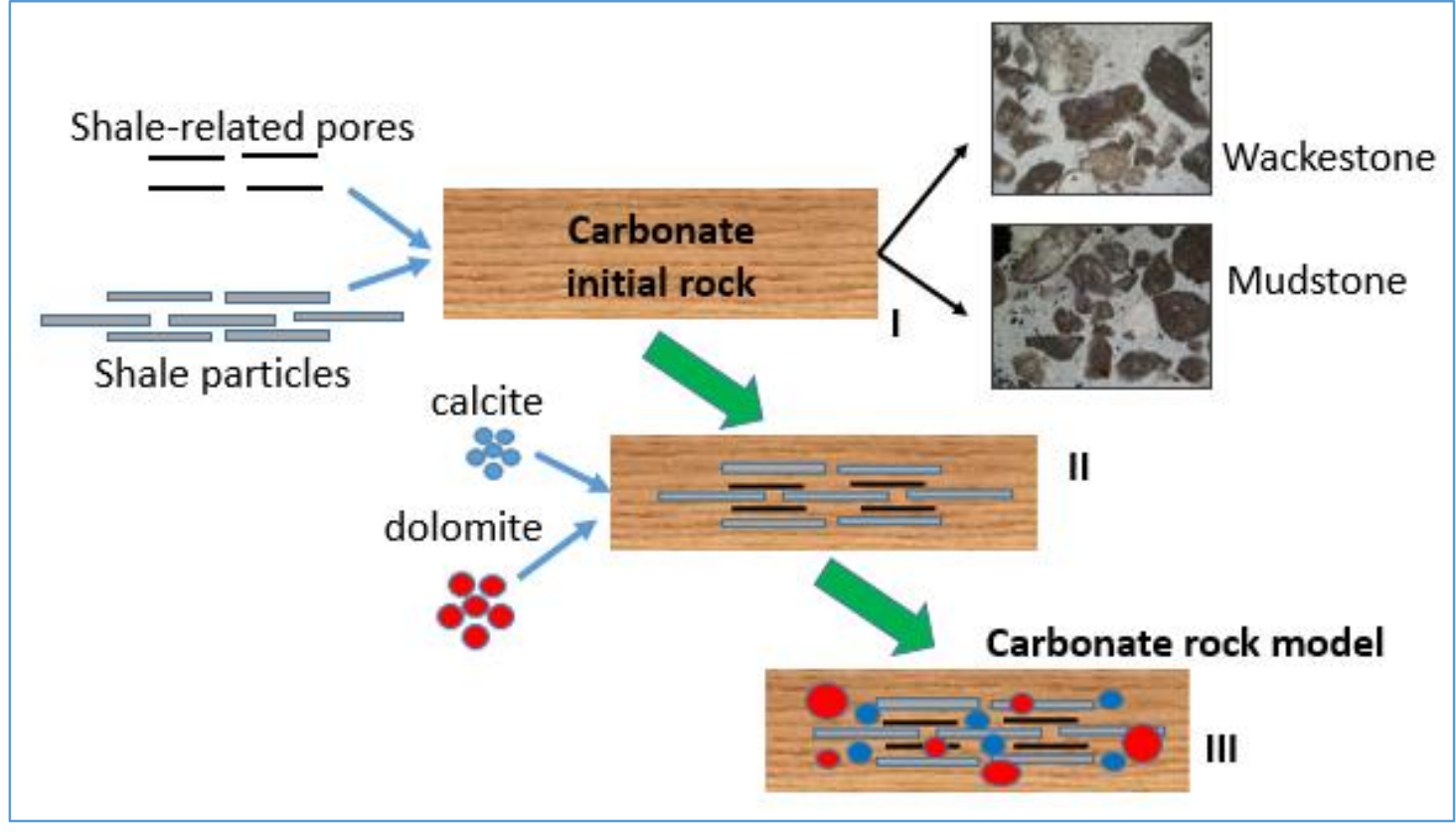

Fig 2. Simplification model to make the carbonate rock sample using effective medium theory. 


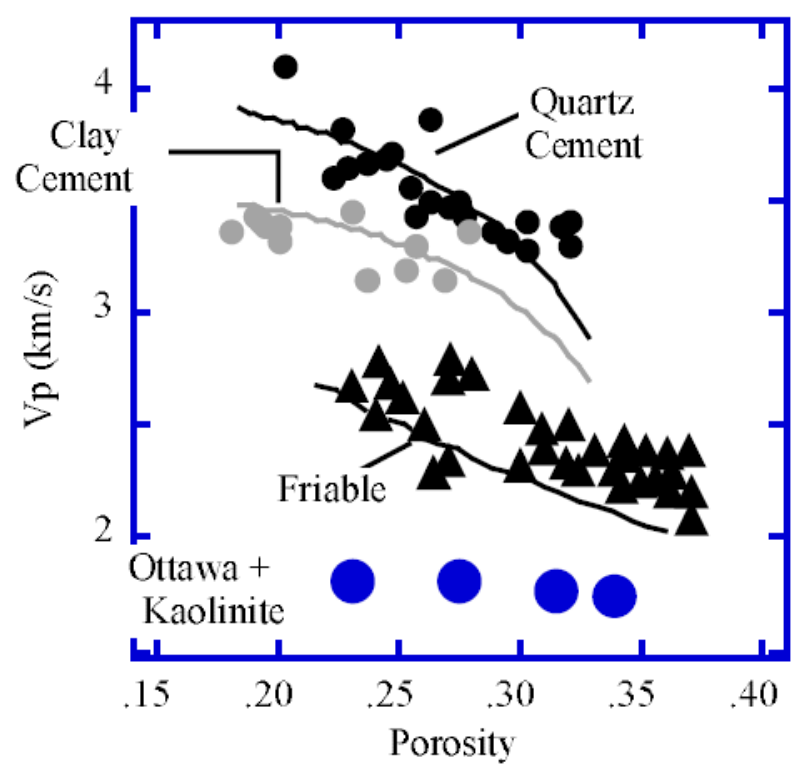

Fig 3. The elastic-wave velocity versus porosity for quartz- and clay cemented North Sea sands, friable North Sea sands (the North Sea data and the models are discussed in Dvorkin and Nur, 1996), and hand-made Ottawa sand and kaolinite mixture (data from Yin et al., 1993). All data are for room-dry samples at 30 MPa differential pressure.

The other bounds for an isotropic linear elastic composite, defined as giving the narrowest possible range without specifying anything about the geometries of the constituents, are the HashinShtrikman bounds. When there are only two constituents, the bounds are written as:

$$
\begin{aligned}
& K^{H S \pm}=K_{1}+\frac{f_{2}}{\left(K_{2}-K_{1}\right)^{-1}+f_{1}\left(K_{1}+\frac{4}{3} \mu_{1}\right)^{-1}} \\
& \mu^{H S \pm}=\mu_{1}+\frac{f_{2}}{\left(\mu_{2}-\mu_{1}\right)^{-1}+2 f_{1}\left(K_{1}+2 \mu_{1}\right) /\left[5 \mu_{1}\left(K_{1}+\frac{4}{3} \mu_{1}\right)\right]}
\end{aligned}
$$

\section{Method}

The reservoir parameters were obtained from a cross-section of 2D seismic data and the welllogging borehole data. The well-logging data (Well - 01) is shown by Figure 4.

The research's flow chart shown by Figure 5 . Characteristic of reservoir rock could be known from geological and seismic data input which could separated top and bottom of reservoir rock also its geometry. Log data was used for making the crossplot with rock physics modelling. Further this could separated zones which rich of shale and less of shale.

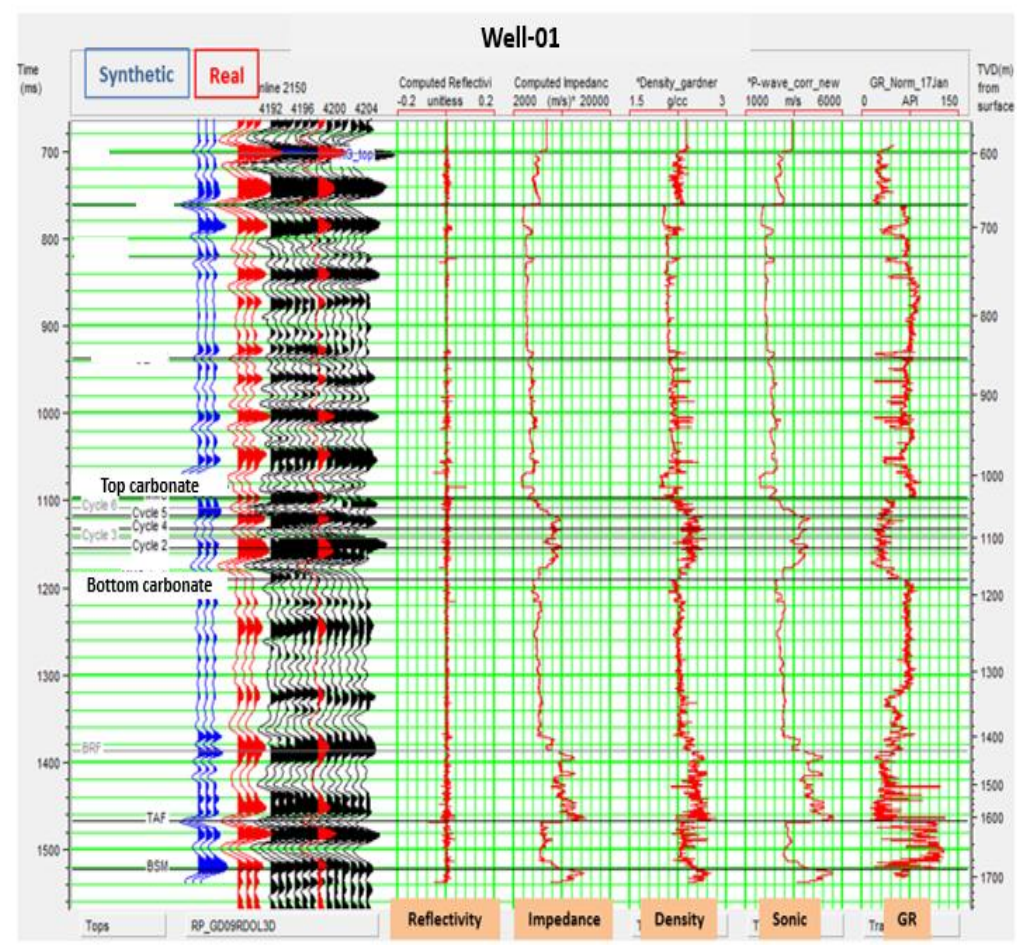

Figure 4. Well-logging data of study area (Well-01). 


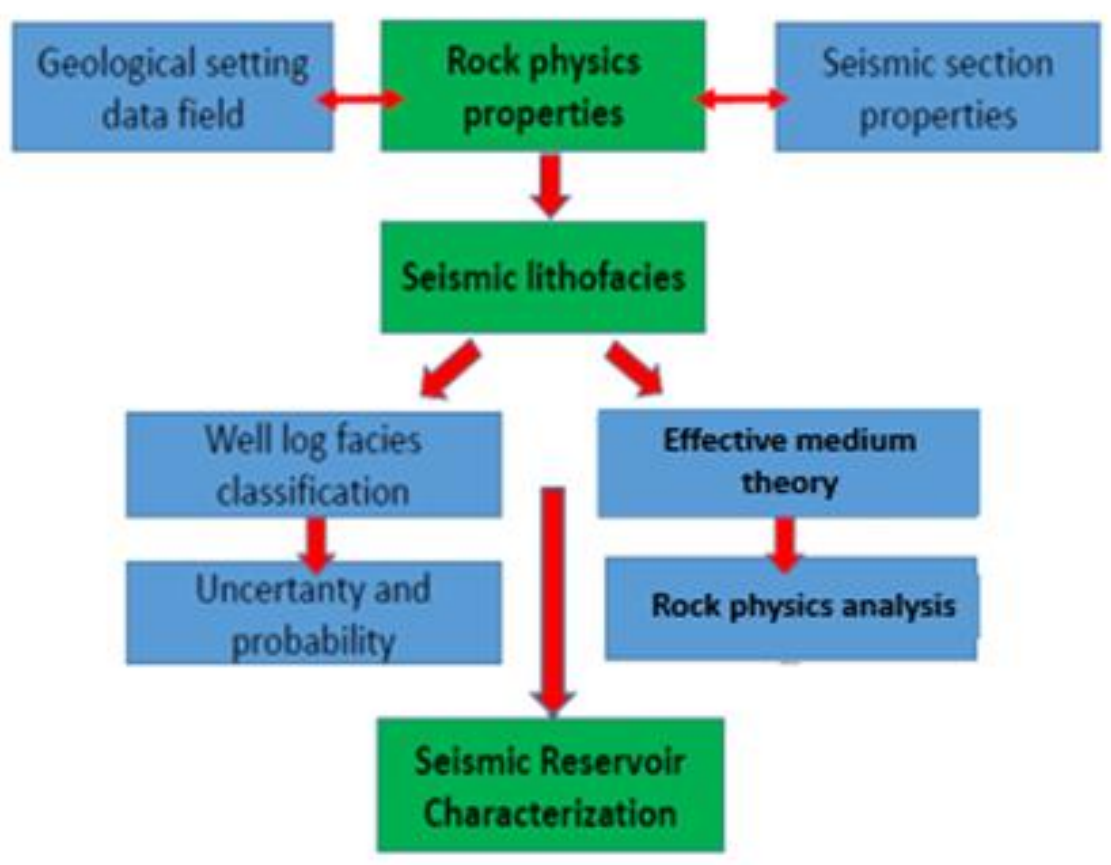

Figure 5. Flow chart of the research.

\section{Result and Discuss}

2D seismic interpretation of study area shown by Figure 6 . Carbonate reservoir characterized by the geometry that resemble a built-up carbonate and the flatspot of sesimic response. In addition, Figure 4 shown the top (1000 ms) and the bottom (1060 ms) of reservoir that characterized with the changes of contrast acoustic impedance, density, and P-wave velocity. Also there is an exsistence of a very long fault structure near the reservoir (left side).

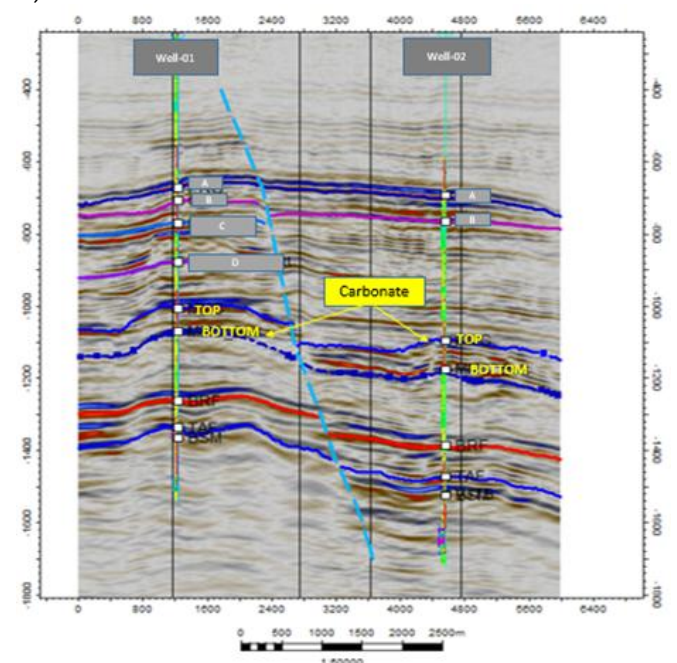

Figure 6. 2D seismic interpretation in study area. From well-01 data and seismic response, we could see that the geometry of carbonate reservoir shown by the existence of flatspot which resemble a built-up of carbonate rock.
Gamma ray crossplot and acoustic impedance shown by Figure 7 . The high gamma ray shown the influence of shally-cemented in carbonate rock. Gamma ray data vs acoustic impedance separated zone of reservoir rock which rich of shale and less of shale.
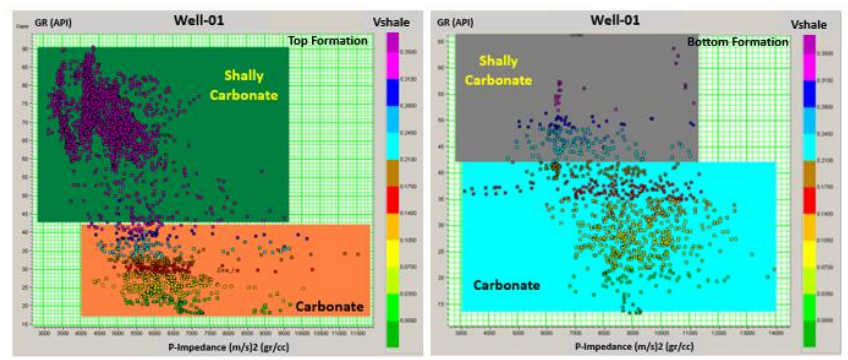

Figure 7. Gamma ray crossplot vs acoustic impedance. The high gamma ray shown the influence of shally-cemented in carbonate rock.

Rock physics modeling in reservoir rock used the effective medium theory Voitgt, Reuss and HashinShtrikman bounds. Modeling of composite reservoir rock (Figure 2) gave the result shown by curve in Figure 8. Elastic moduly (bulk moduly and shear moduly) decreasing proporsionally with increasing porosity value. The influence of shally-cemented in carbonate rock causing the high bulk moduly. Figure 8c shown the reservoir rock zone which rich of shale and less of shale. 

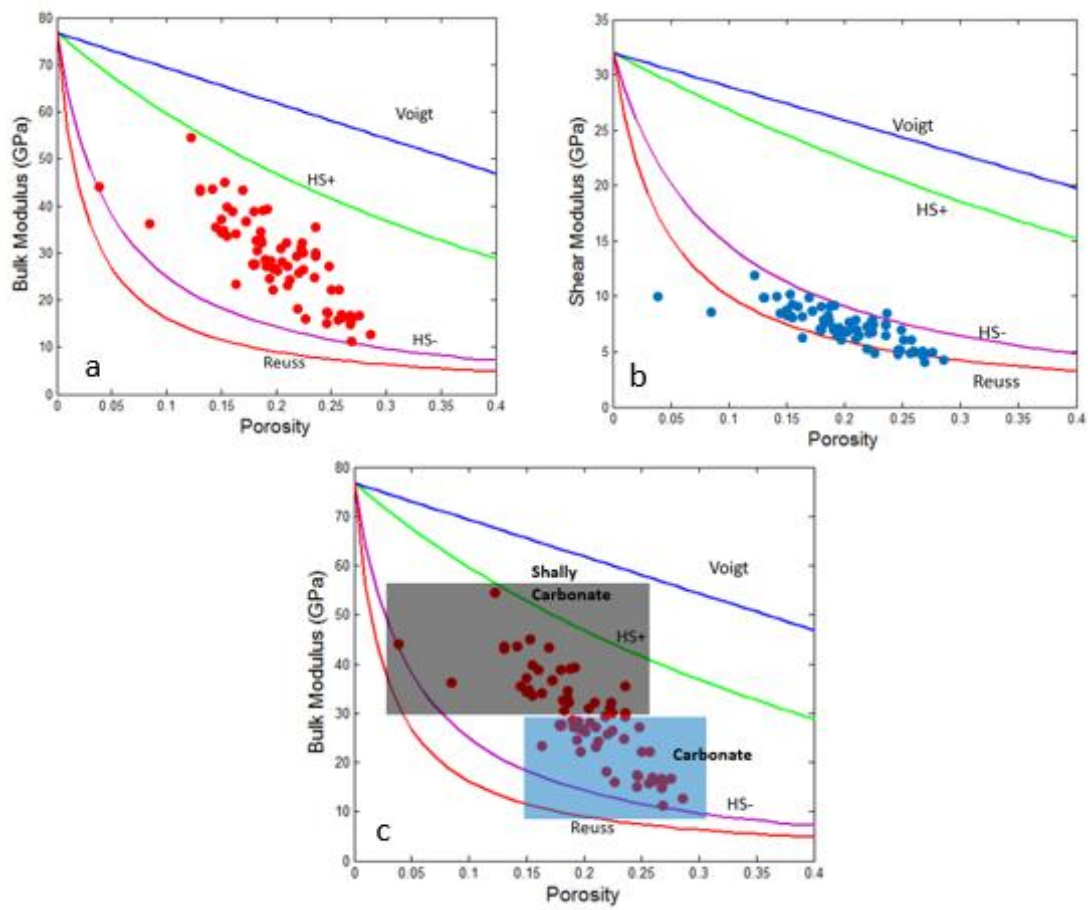

Figure 8. Effective medium theory using Voigt, Reuss, and Hashin-Shtrikman bounds. Figure 8a is bulk moduly, Figure 8b is shear moduly, and Figure $8 \mathrm{c}$ is prediction of shale-carbonate and initial carbonate zone.

P-wave velocity values is decreasing proporsionally with increasing porosity value. According to Figure 3 , the effect of shallycemented in carbonate gave a higher P-wave velocity than the initial carbonate rock (Figure 9).

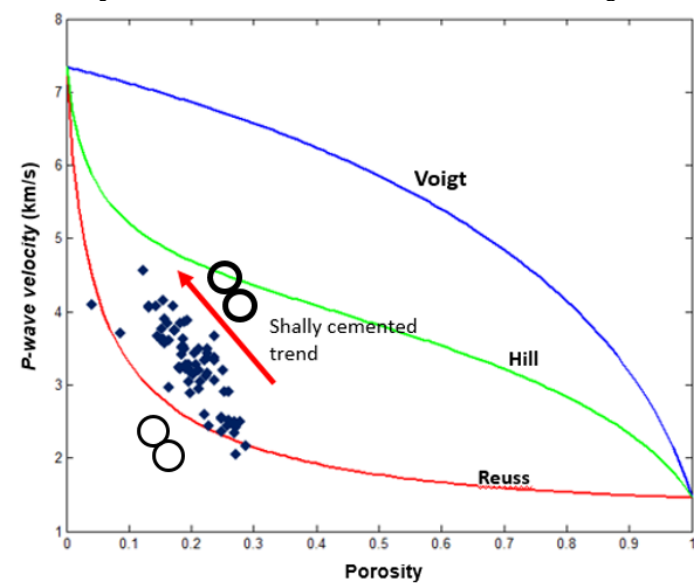

Figure 9. Effect shale-cemented in carbonate reservoir rock to P-wave velocities value. Contact shale cemented in carbonate reservoir rock. Shally cemented on the carbonate rock obtain the P-wave velocity higher than initial carbonate reservoir rock.

\section{Concluding Remarks}

The conclusions from this paper are (1) Geometry and Top-Bottom reservoir carbonate rock can be known from log data and seismic section, (2) The effect of shally-cemented on reservoir rock characterized by an enhancment in bulk moduly and P-wave velocity also a reduction in porosity, and (3) Rock physics modeling and log data could separated the characteristic of reservoir rock which shally-cemented and its initial carbonate.

\section{Acknowledgements}

Thanks to the supporting partner in this research which was partly provided by LPPM of Institut Teknologi Sumatera and Universitas Padjajaran.

\section{References}

[1] Anselmetti, F. S., and Eberli, G. P., 1997, Sonic velocity in carbonate sediments and rocks; in Palaz, I., and Marfurt, K.J., Eds., Carbonate Seismology: Soc. Expl. Geophys., Tulsa, 53-74.

[2] Avseth, P., and Mavko, G., 1995, The influence of diagenesis on the acoustic properties of grainsupported siliciclastic sedimentary rocks: Annual Meeting, Stanford Rock Physics and Borehole Geophysics Project, 58, Paper B1.

[3] Bryant, S., and Raikes, S., 1995, Prediction of elasticwave velocities in sandstones using structural models: Geophysics, 60, 437-446.

[4] Dvorkin, J., and Nur, A., 1996, Elasticity of HighPorosity Sandstones: Theory for Two North Sea Datasets, Geophysics, 61, 1363-1370.

[5] Jizba, D., 1991, Mechanical and Acoustical Properties of Sandstones and Shales: Ph.D.-Thesis, Stanford University.

[6] Mavko, G., and Nur, A., 2009. The Rock Physics Handbook, Second Edition Tools for Seismic Analysis of Porous Media. Cambridge University Press The Edinburgh Building, Cambridge CB2 8RU, UK

[7] Sukmono, S. 2002. Seismic Inversion and AVO Analysis for Reservoir. Program Studi Teknik Geofisika ITB. Bandung. Indonesia.

[8] Vernik, L., 1994, Predicting lithology and transport properties from acoustic velocities based on petrophysical classification of siliciclastics. Geophysics, 59, 420-427. 